\title{
Lip and Face Edema Due to Face Presentation
}

\author{
๑ Hülya Özdemir1, ๑ Merve Öztürk2, ๑ Hülya Bilgen1, ๑ Eren Özek1 \\ ${ }^{1}$ Marmara University Faculty of Medicine, Department of Pediatrics, Division of Neonatology, Istanbul, Turkey \\ 2 Marmara University Faculty of Medicine, Department of Pediatrics, Istanbul, Turkey
}

\begin{abstract}
A $3100 \mathrm{~g}$ male appropriate for gestational age baby was born at 40 weeks to a healthy mother by normal spontaneous vaginal delivery. Apgar scores were 9 and 10 at the $1^{\text {st }}$ and $5^{\text {th }}$ minutes, respectively. Physical examination of the infant's respiratory system, cardiovascular system and his abdominal examination were normal; neurological examination revealed no abnormality. Suspicious syndromic facial appearance with modarete edema at the baby's lips and face was evident and he had bruising on the left nasolabial groove and on both cheeks. We aimed to emphasize the fact that facial edema due to soft tissue trauma seen in newborns born with face presentation may be misinterpreted as a sign of a syndrome. However, careful anamnesis, thorough physical examination, and close follow-up could ensure the diagnosis of birth trauma.

Keywords: Birth trauma, face presentation, newborn
\end{abstract}

\section{Introduction}

Neonatal facial birth injuries are easily recognizable, but they are the most under-reported form of birth injuries. Newborn infants with face presentation usually have severe facial edema, facial bruising or ecchymosis. Anything that delays or prevents flexion such as fetal anomalies, contracted pelvis, fetopelvic disproportion or cord around the neck can contribute to face presentation (1). Repeated vaginal examination to assess the presenting part and the progress of labor may lead to bruises in the face as well as damage to the eyes. We aimed to emphasize the fact that facial edema due to soft tissue trauma seen in newborns born with face presentation may be misinterpreted as a sign of a syndrome. However, careful anamnesis, thorough physical examination, and close follow-up could ensure the diagnosis of birth trauma.

\section{Case Report}

A $3100 \mathrm{~g}$ male appropriate for gestational age baby was born at 40 weeks to a healthy mother by normal spontaneous vaginal delivery. Apgar scores were 9 and 10 at the $1^{\text {st }}$ and $5^{\text {th }}$ minutes, respectively. His parents were healthy and had no consanguinity. The mother did not attend routine prenatal care on a regular basis and did not receive any medication during pregnancy. The weight of the infant was $3100 \mathrm{~g}$ (1050 percentile), height was $48 \mathrm{~cm}$ (10-50 percentile), and head circumference was $35 \mathrm{~cm}$ (50-90 percentile). Physical examination of the infant's respiratory system, cardiovascular system, and his abdominal examination were normal, as was his neurological examination. Suspicious syndromic facial appearance with moderate edema at the baby's lips and face was evident and he had bruising on the left nasolabial groove and on both cheeks (Figure 1). No accompanying lesions were observed in the mouth. The baby was breastfed without any problem after delivery. Edema completely resolved about four hours after birth (Figure 2). Written informed consent was obtained from the patient's parents for the publication of this case report.

\section{Discussion}

Birth trauma is the physical damage of the baby during the birth process due to the exposition of mechanical effects (2). Birth traumas are less reported in cesarean 


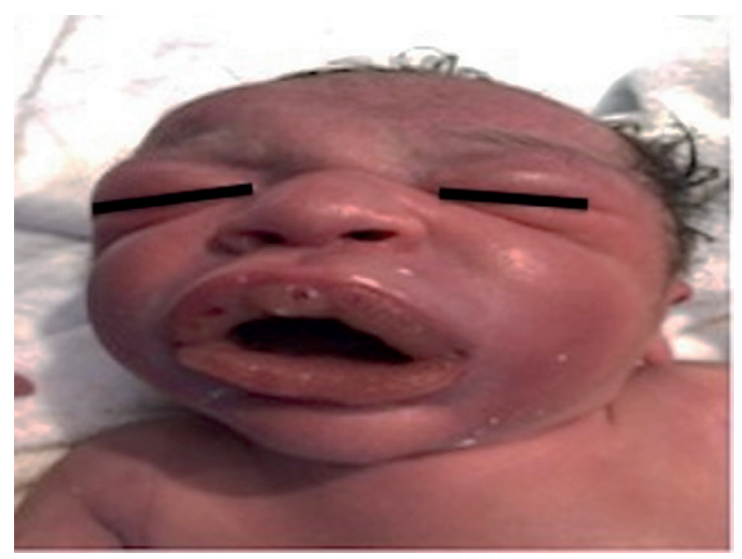

Figure 1. Infant's face appearence at the first hour of life

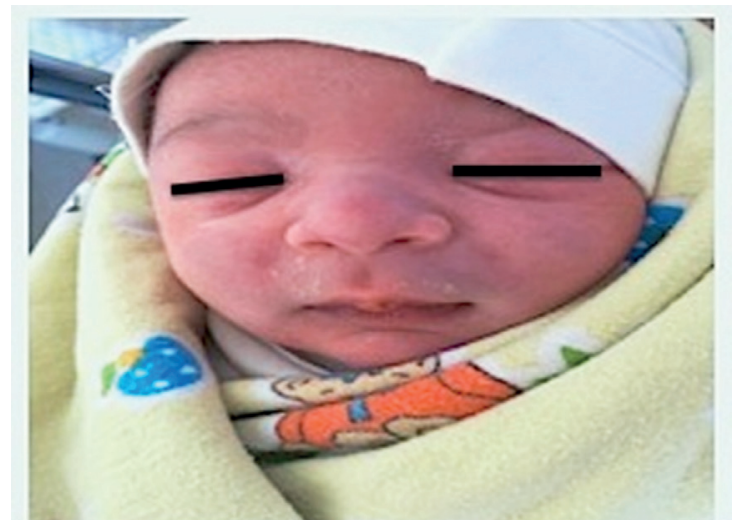

Figure 2. Infant's face appearence at the fourth hour of life

deliveries (3). The incidence of birth trauma has decreased with the improvements in obstetric care and prenatal diagnosis; and birth trauma frequency has been reported as $2 \%$ in vaginal and $1.1 \%$ in cesarean deliveries $(4,5)$. Risk factors include macrosomia, preterm delivery, prolonged labor, maternal obesity, fetal presentation anomalies and operative delivery (forceps or vacuum) (6). The most common type of birth trauma is soft tissue trauma, which can be seen as ecchymosis on the skin, petechia, laceration and subcutaneous fat necrosis (7). Genital edema and ecchymosis can be seen on breech presentation. Laceration is the most commonly seen soft tissue trauma in cesarean delivery (3).

The prevalence of face and brow presentation has been reported as $0.14 \%$ to $0.54 \%$ in deliveries (8). Face presentation is associated with multiparity, macrosomia, cephalopelvic disproportion, prematurity, polyhydramnios, and fetal anomalies (such as anencephaly or cervical mass) (9). Newborn infants with face presentation usually have severe facial edema, facial bruising or ecchymosis. They mostly recover within 24 to 48 hours. Eyelid swelling and ulceration, retinal or subconjunctival hemorrhage may occur as a result of nasal septum dislocation and ocular trauma may occur due to the pressure of the mother's symphysis pubis or sacral promontorium on the baby's face $(1,9)$. Severe respiratory distress has been reported in certain cases due to a swollen tongue (10). In our case, significant facial and labial swelling was observed as well as ecchymosis on cheeks due to facial presentation, and they recovered spontaneously within hours. There were no findings in other parts of the body related to birth trauma. In conclusion, we aimed to emphasize the fact that facial edema due to soft tissue trauma seen in newborns born with face presentation may be misinterpreted as a sign of a syndrome. However, with careful anamnesis, thorough physical examination, and close follow-up it would be possible to make a certain diagnosis of birth trauma.

\section{Ethics}

Informed Consent: Written informed consent was obtained from the patient's parents for the publication of this case report.

Peer-review: External and internal peer-reviewed.

\section{Authorship Contributions}

Medical Practices: M.Ö., H.Ö., Data Collection or Processing: H.Ö., M.Ö., H.B., Analysis or Interpretation: H.Ö., M.Ö., H.B., E.Ö., Literature Search: H.Ö., M.Ö., H.B., Writing: H.Ö., H.B.

Conflict of Interest: No conflict of interest was declared by the authors.

Financial Disclosure: The authors declared that this study received no financial support.

\section{References}

1. Cunningham FG, Leveno JK, Bloom SL. Delivery. In: Cunningham FG (ed). Williams Obstetrics, 24rd ed. McGrawHill, 2014:466-7.

2. Gomella TL. Traumatic Delivery. In: Gomella TL, Cunningham MD, Eyal FG, Tuttle D (eds). Neonatology Management, Procedures, on call problems, Diseases and Drugs. 7th ed. New York, The McGraw-Hill, 2013;379-86.

3. Li T, Rhoads GG, Smulan J, Demisie K, Wartenberg D, Kruse L. Physician Cesarean Delivery Rates and Risk Adjusted Perinatal Outcomes. Obstet Gynecol 2003;101:1204-12.

4. Alexander JM, Leveno KJ, Hauth $\mathrm{J}$, et al. Fetal injury associated with cesarean delivery. Obstet Gynecol 2006;108:885-90.

5. Demissie K, Rhoads GG, Smulian JC, et al. Operative vaginal delivery and neonatal and infant adverse outcomes: population based retrospective analysis. BMJ 2004;329:24-9.

6. Hankins GD, Clark SM, Munn MB. Cesarean section on request at 39 weeks: impact on shoulder dystocia, fetal trauma, neonatal encephalopathy, and intrauterine fetal demise. Semin Perinatol 2006;30:276-87.

7. Rosenberg A. Traumatic birth injury. Neo Reviews 2003;4:270-6.

8. Tapisiz OL, Aytan H, Altinbas SK, et al. Face presentation at term: a forgotten issue. J Obstet Gynaecol Res 2014;40:1573-7.

9. Akangire A, Carter B. Birth injuries in neonates. Pedi Rev 2016;37:451-62.

10. Sharmila $V$, Babu TA. Unusual birth trauma involving face: a completely preventable iatrogenic injury. J Clin Neonatol 2014;3:120-1. 